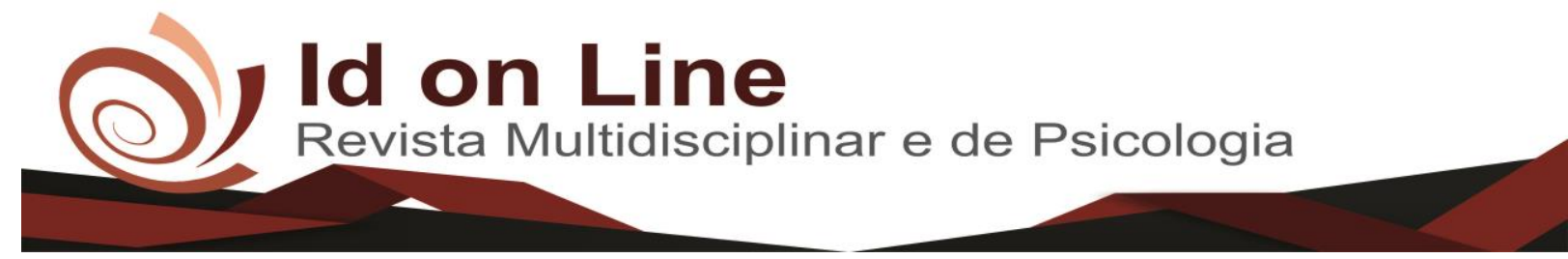

Artigo

\title{
A Terapia como Extensão na Formação do Acadêmico em Psicologia
}

\author{
Rosângela de Mello Owicki Nunes ${ }^{1}$, Marjane Bernardy Souza ${ }^{2}$
}

\begin{abstract}
Resumo: O objetivo desta pesquisa foi conhecer algumas características de acadêmicos que estão realizando o estágio profissionalizante em Psicologia, identificando fatores favoráveis à prática da psicoterapia, aspectos que desfavoreçam sua adoção durante o período de graduação. Foram consultados acadêmicos de Psicologia de seis campi de uma universidade particular do Rio Grande do Sul. A investigação contou com um questionário estruturado, os dados foram coletados e analisados através do Google Forms. O estudo identificou que 84,4\% dos estudantes realizaram psicoterapia pessoal em algum momento da graduação. A adoção pessoal de psicoterapia é considerada cara por $71,1 \%$ da amostra e $95,6 \%$ afirmaram que fariam uso do recurso caso fosse gratuito e $88,9 \%$ considera que seria adequado para sua formação. $\mathrm{O}$ serviço de psicoterapia dentro da graduação seria de considerável relevância, devido às dificuldades financeiras e as realidades psíquicas enfrentadas. $\mathrm{O}$ apoio psicológico permitiria a geração de novos significados para a vivência acadêmica.
\end{abstract}

Palavras-chave: Formação Acadêmica. Curso de Psicologia. PsicoterapiaPessoal.

\section{Therapy as Extension in Formation Degree in Psychology}

\begin{abstract}
Research's objective was to know some characteristics of academics who are carrying out the professionalizing internship in Psychology, identifying factors favorable to the practice of psychotherapy, as well as aspects that underestimate its adoption during the graduation period. Psychology students from six campuses of a private university in Rio Grande do Sul were consulted regarding the adoption of personal psychotherapy during their academic formation. The research had a structured questionnaire, it was collected and analyzed using the Google Forms tool. The study identified that $84.4 \%$ of students performed personal psychotherapy at some point in their undergraduate degree. Personal adoption of psychotherapy is considered expensive by $71.1 \%$ of the participants and $95.6 \%$ stated that they would enjoy the resource if they had access to free service and $88.9 \%$ considered that it was appropriate for their academic formation. The service of psychotherapy within the graduation would be of considerable relevance, because to the financial difficulties and the psychic realities faced. The psychological support would allow the generation of new meanings for the academic experience.
\end{abstract}

Keywords: Academic Education. Psychology Course, Personal Psychotherapy

\footnotetext{
${ }^{1}$ Acadêmica do Curso de Psicologia - Universidade Luterana do Brasil - São Jerônimo.

Contato: rosangela.owicki@gmail.com

${ }^{2}$ Graduação em Psicologia-Bachalerado pela Universidade do Vale do Rio dos Sinos (UNISINOS), Psicologia-Licenciatura pela Universidade Federal do Rio Grande do Sul (UFRGS), especialização em Aconselhamento das Relações Familiares pela Pontifícia Universidade Católica do Rio Grande do Sul (PUCRS) e mestrado em Família e Sistemas Sociais pelo Instituto Superior Miguel Torga - Coimbra-Portugal (ISMT-2004), especialista em Psicologia no Trânsito (CFP) e especialista em Psicologia Jurídica (CFP). Perita em Avaliação Psicológica no Departamento de Trânsito - DETRAN/RS. Coordenadora e professora adjunta do Curso de Psicologia da Universidade Luterana do Brasil - São Jerônimo e Coordena o Grupo de Pesquisa sobre Violência. Contato: marjanesouza@yahoo.com.br
} 


\section{Introdução}

A formação de Psicólogo é regulamentada no Brasil pela Resolução da Câmara de Ensino Superior (CES) do Conselho Nacional de Educação (CNES) nº 05, de 15 de março de 2011, que institui as Diretrizes Curriculares Nacionais. Discussões e organizações foram preparadas para promover a observação e o acompanhamento das competências e habilidades do futuro psicólogo, onde foi proposta e regulamenta a criação de Serviço de Psicologia com Estágios Supervisionados, que devem constar no Projeto dos Cursos de Psicologia, onde os acadêmicos possam fazer atendimento à comunidade.

Diante das demandas impostas ao acadêmico de Psicologia, como o anseio em auxiliar o próximo, o conflito entre sua subjetividade e a do outro, e aos desafios do início da carreira, entende-se ser relevante trazer à tona o processo de formação acadêmica e o cuidado à saúde mental desse futuro psicólogo através da psicoterapia como extensão de sua graduação.

Para tanto, estabelece-se os seguintes objetivos desse estudo: conhecer algumas características do acadêmico que está realizando o estágio profissionalizante, identificar fatores favoráveis a prática da psicoterapia e levantar alguns aspectos que desfavoreçam a psicoterapia na graduação.

\section{A formação acadêmica do psicólogo}

Durante a graduação, a trajetória pessoal dos acadêmicos pode influenciar no aparecimento de angústias, insegurança e dúvidas, desencadeadas, em alguns casos, pelo próprio curso, devido a rotinas de estudos que mobilizam sentimentos muito particulares, desafio que instiga atentar para a importância da formação pessoal e profissional estarem alinhadas (MEIRA e NUNES, 2005;SILVA e SOARES, 2014).

As mudanças do contexto na sociedade, aliadas à subjetividade humana, necessitam de atenção e intervenções, pois interferem nas práticas individuais e coletivas. Dessa forma, tornase fundamental observar e definir as questões que envolvem os pensamentos e sentimentos dos estudantes de Psicologia que comporão o contexto intersubjetivo na sua prática profissional (CAMBUÍ e NEME, 2014). 
Aprender a ser psicoterapeuta é resultado da visão de mundo e modo de agir do indivíduo, independente da técnica desenvolvida pelo acadêmico. Um estudo em que doze dentre os dezoito estagiários fizeram psicoterapia coaduna com a conclusão de Kichler e Serralta (2014) em que "o tratamento pessoal foi considerado de primordial importância para a consciência e resolução de problemas pessoais que pudessem interferir no processo terapêutico".

\section{Metodologia}

Trata-se de uma pesquisa de abordagem quantitativa com objetivo exploratório, que visa proporcionar maior familiaridade com o problema, com vistas a torná-lo mais explícito ou a construir hipóteses a partir de um questionário. Optou-se por um conjunto de questões que foram respondidas a partir do ponto de vista dos pesquisados com garantia de anonimato. Além disso, é um método rápido, de baixo custo e não requer treinamento prévio (GIL, 2010).

\section{Participantes}

Participaram da pesquisa45acadêmicos matriculados na disciplina de estágio profissionalizante de 06 campi do curso de Psicologia de uma universidade privada do Rio Grande do Sul.

\section{Instrumento}

Foi elaborado um questionário estruturado com 19 perguntas fechadas, realizado em duas etapas: a primeira com 07questõessocioeconômicasvisava identificar características dos estagiários como a idade, o estado civil, com quem mora, se possui trabalho remunerado, forma de pagamento da faculdade, auxílio de custo e renda aproximada. 
A segunda parte do questionário conteve12 perguntas fechadas, abordando questões relacionadas aos temas de estudo: motivo de escolha do curso, a importância da psicoterapia, dificuldades que desfavorecem a adoção desse recurso e pontos favoráveis ao acompanhamento psicoterápico.

O questionário passou pela avaliação de pares, realizadas por professoras responsáveis pelas supervisões de estágios. Foi aprovado com sugestões de alteração, que foram aceitas e efetuadas.

\section{Procedimentos para coleta de dados}

Após a autorização da coordenação e envio dos e-mails dos estagiários, foi realizado contato com as coordenadoras dos cursos de Psicologia da universidade privada em questão para que o questionário online fosse enviado para 192 acadêmicos no período compreendido entre 07 e 17 de outubro de 2017.

O questionário foi Acompanhado do Termo de Consentimento Livre e Esclarecido (TCLE). O preenchimento das questões ocorreu sem identificação e as respostas foram aceitas até 17 de outubro de 2017 para que houvesse tempo hábil para compilação de dados e discussão.

De acordo com a Resolução 510/2016, a pesquisa de opinião é isenta de registro no CEP/CONEP, ou seja, não é necessária a validação pelo Comitê de Ética. O estudo pautou-se pela Resolução 196/96 do Conselho Nacional de Saúde (CNS), que garante autonomia, beneficência, não maleficência e justiça.

\section{Análises dos dados}

Os dados foram compilados e avaliados pela ferramenta Google Forms, através de gráficos, utilizando parâmetro estatístico descritivo (porcentagem) com a finalidade de gerar tabelas referentes aos objetivos propostos. As tabelas foram criadas com o programa Microsoft Excel 2007 com análise descritiva sobre resultado de questões de múltipla escolha. 


\section{Apresentação e discussão dos resultados}

Os resultados apontam que dos 192 questionários online enviados entre os dias 7 e 10 de outubro e 2017, obteve-se uma amostra de 45 estagiários que aceitaram participar da pesquisa. Sobre o restante do grupo não há informações do (s) motivo (s) pelo (s) qual (quais) não participaram, ainda que a primeira pergunta do questionário sugerisse opções como "Não aceito, pois não participo de pesquisas" e "Não aceito, pois o assunto não é de meu interesse".

Para conhecer algumas características dos estagiários pesquisados, as respostas foram agrupadas através de questões socioeconômicas, entre elas idade, estado civil, se possui trabalho remunerado, renda aproximada em salários mínimos, com quem divide moradia, forma de pagamento da faculdade e se possui auxílio de custo.

Observou-se que o perfil predominante na amostra é jovem, adulto e autodeclarado solteiro. Desses, 51,1\%,moram com marido ou esposa, o que é possível compreender como relacionamento estável, no qual as responsabilidades econômicas demandam mais investimentos do que morar com os pais (tabela 1).

Tabela 1: Dados Socioeconômicos. 2017

\begin{tabular}{|c|c|c|}
\hline Idade & $\mathbf{N}$ & $\%$ \\
\hline Entre 17 e 30 anos & 20 & $44,4 \%$ \\
\hline Entre 30 e 50 anos & 15 & $33,3 \%$ \\
\hline Acima de 50 anos & 10 & $22,2 \%$ \\
\hline Total & 45 & $100,0 \%$ \\
\hline \multicolumn{3}{|l|}{ Estado Civil } \\
\hline Solteiro (a) & 26 & $57,8 \%$ \\
\hline Casado (a) & 19 & $42,2 \%$ \\
\hline Total & 45 & $100,0 \%$ \\
\hline \multicolumn{3}{|l|}{ Trabalho Remunerado } \\
\hline Sim & 23 & $51,1 \%$ \\
\hline Não & 22 & $48,9 \%$ \\
\hline Total & 45 & $100,0 \%$ \\
\hline \multicolumn{3}{|l|}{ Renda Aproximada } \\
\hline Até 2 salários mínimos & 15 & $55,6 \%$ \\
\hline $\begin{array}{l}\text { Entre } 2 \text { e } 4 \text { salários } \\
\text { mínimos }\end{array}$ & 6 & $22,2 \%$ \\
\hline $\begin{array}{l}\text { Acima de } 4 \text { salários } \\
\text { mínimos }\end{array}$ & 6 & $22,2 \%$ \\
\hline Total & 27 & $100,0 \%$ \\
\hline
\end{tabular}




\begin{tabular}{|c|c|c|} 
Convive & & \\
Pais & 16 & $35,6 \%$ \\
Marido/Esposa & 23 & $51,1 \%$ \\
Amigos & 0 & $0,0 \%$ \\
Sozinho (a) & 6 & $13,3 \%$ \\
Total & $\mathbf{4 5}$ & $100,0 \%$ \\
Faculdade & & \\
Particular & 25 & $55,6 \%$ \\
Financiada & 7 & $15,6 \%$ \\
Programa Governamental & 13 & $28,9 \%$ \\
Total & $\mathbf{4 5}$ & $100,0 \%$ \\
Auxílio Faculdade & & \\
Pais & 17 & $77,3 \%$ \\
Tios & 1 & $4,5 \%$ \\
Avós & 1 & $4,5 \%$ \\
Empresa & 3 & $13,6 \%$ \\
Total & $\mathbf{2 2}$ & $100,0 \%$ \\
\hline
\end{tabular}

Assim, conciliar responsabilidades pessoais, acadêmicas e profissionais demanda um equilíbrio entre diferentes exigências decorrentes de novas formas de vivências nos diferentes ambientes no contexto atual, acarretando uma nova dinâmica nos papéis nas famílias e nas organizações (JÚNIOR et al., 2013; SEVERIANO, 2013).

O trabalho remunerado com renda média de até dois (02) salários mínimos é destacado na amostra, estando o auxílio de custos dos pais presente em 77,3\% dos estagiários, de acordo com a Tabela 1. Esse auxílio de custo pode abranger custos menores que a mensalidade como transporte, alimentação, fotocópias e livros, entre outros, visto que apenas 22 acadêmicos se posicionaram nesse quesito. Ainda sobre sustento, é possível notar uma discrepância entre quantos possuem trabalho remunerado e quantos possuem renda, o que leva à suposição de que existe algum meio de renda não formalizado.

O pagamento da faculdade é feito integralmente por $55,6 \%$ da amostra e $28,9 \%$ não pagam ou pagam um valor baixo, pois contam com Programas Governamentais como Programa Universidade para Todos (PROUNI) ou o Programa de Estímulo à Reestruturação e ao Fortalecimento das Instituições de Ensino Superior (PROIES).

Foram reunidas na tabela 2 as respostas obtidas com as questões 08, 09, 10, 17, 18 e19 do questionário, aos aspectos favoráveis à psicoterapia na formação do psicólogo: 
Tabela 2: Fatores Favoráveis. 2017

\begin{tabular}{c|c|c}
\hline Fatores Favoráveis a Psicoterapia & $\mathrm{N}$ & $\%$ \\
Considera importante fazer enquanto a & & \\
graduação & & \\
Sim & 45 & $100,0 \%$ \\
Não & 0 & $0,0 \%$ \\
Total & 45 & $100,0 \%$ \\
Influência dos colegas & & \\
Sim & 31 & $68,9 \%$ \\
Não & 14 & $31,1 \%$ \\
Total & 45 & $100,0 \%$ \\
Fez em algum momento enquanto na & & \\
graduação & & \\
Sim & 38 & $84,4 \%$ \\
Não & 7 & $15,6 \%$ \\
Total & 45 & $100,0 \%$ \\
Prática de estágio torna necessária a & & \\
procura & & \\
Sim & 43 & $95,6 \%$ \\
Não & 2 & $4,4 \%$ \\
Total & 45 & $100,0 \%$ \\
Sim & & \\
Não & 45 & $100,0 \%$ \\
Total & 0 & $0,0 \%$ \\
O curso estimula a procura & 45 & $100,0 \%$ \\
\hline
\end{tabular}

Entre os dados relevantes em relação à psicoterapia como extensão durante a formação, a escolha do curso é considerada por $86,7 \%$ como mais importante para entender o outro do que a si mesmo. Essa motivação, aliada às demandas impostas pela vida acadêmica, como cursos de extensão, horas complementares e possíveis estágios extracurriculares ou obrigatórios, levam o estudante a seguir o fluxo, no anseio de conhecer e dominar técnicas. Dutra (2013) alerta para o fato de que comumente a teoria é privilegiada e reconhecida na formação do profissional de Psicologia, o que reforça a ideia do psicólogo como um técnico.

Conforme a consulta, $100 \%$ dos estagiários concordam que é importante fazer psicoterapia enquanto acadêmico de Psicologia, ainda que não seja obrigatório, tendo $84,4 \%$ já realizado a psicoterapia em algum momento da graduação, um fator importante dado que a formação inclui transformações e mudanças, entre elas o autoconhecimento, o reconhecimento 
de suas limitações e potencialidades e a necessidade de ter suas demandas atendidas. Entendese que as demandas apresentadas por pacientes, grupos ou instituições se encontrarão, pelo menos em algum momento, com as demandas internas do futuro psicólogo. Calligaris (2008) menciona que o "tornar-se psicoterapeuta" se dará fora da faculdade, depois ou durante da graduação, quando o psicoterapeuta se coloca em tratamento, enfatizando que isso não faz parte do curso, pois não tem como ser avaliado, não havendo garantia de confidencialidade nem qualidade da relação terapêutica.

O fato de outros acadêmicos do curso de Psicologia estar em tratamento pessoal influência 68,9\%, dos consultados na reflexão sobre também aderir à psicoterapia. A amostra demonstra que existe reconhecimento da importância de, durante a graduação, aderir ao tratamento pessoal como extensão de sua formação, já que nesse momento importante de estágio profissionalizante coloca-se o aprendizado teórico em prática, confrontando a subjetividade do outro com a própria, muito embora a consciência e a vontade não sejam suficientes diante de fatores desfavoráveis e questões socioeconômicas apresentados.

No que se refere ao estímulo institucional do curso de psicologia para que o acadêmico faça psicoterapia como extensão, $100 \%$ da amostra identificou que o estímulo existe, enquanto 95,6\% da amostra, consideram que o período da prática de estágio representa o momento mais propício para a adoção de psicoterapia. Segundo Oliveira et al (2016), é importante não haver uma mera reprodução de informações, pois na área da saúde existe o risco da desumanização, o que sem um olhar atento, pode gerar uma despersonalização na relação de cuidar. A respeito dessa temática, $84,4 \%$ dos consultados afirmaram já terem participado de um processo terapêutico, voltando a olhar com cuidado para sua saúde mental

Em se tratando do processo terapêutico, Foucault (1985) e Marcello (2014) descreveram a relação consigo como "a cultura de si", algo que deveria ser valorizado e intensificado na vida, visando que esse fator é determinante para o desenvolvimento e organização da prática individual, item de relevância fundamental para o acadêmico de Psicologia, uma vez que seu anseio por entender o outro implica em ter suas questões pessoais resolvidas para bem se dedicar às demandas do sujeito posto diante de si (ANDRADE et al., 2016).

No que se refere aos fatores desfavoráveis à realização da psicoterapia pessoal durante o processo de graduação, a tabela 3 mostra o agrupamento das respostas obtidas às questões 11 , $12,13,14,15$ e 16 do questionário: 
Tabela 3:Fatores desfavoráveis à realização da psicoterapia pessoal. 2017

\begin{tabular}{|c|c|c|}
\hline Fatores Desfavoráveis a Psicoterapia & $\mathrm{N}$ & $\%$ \\
\hline $\begin{array}{c}\text { Desconforto } \\
\text { Sim } \\
\text { Não } \\
\text { Total } \\
\text { Serviço caro }\end{array}$ & $\begin{array}{l}11 \\
34 \\
45\end{array}$ & $\begin{array}{l}24,4 \% \\
75,6 \% \\
100,0 \%\end{array}$ \\
\hline Sim & 32 & $71,1 \%$ \\
\hline Não & 13 & $28,9 \%$ \\
\hline Total & 45 & $100,0 \%$ \\
\hline Falta de condições financeiras & & \\
\hline Sim & 32 & $71,1 \%$ \\
\hline Não & 13 & $28,9 \%$ \\
\hline Total & 45 & $100,0 \%$ \\
\hline $\begin{array}{c}\text { Falta de tempo } \\
\text { Sim } \\
\text { Não }\end{array}$ & $\begin{array}{l}19 \\
26\end{array}$ & $\begin{array}{l}42,2 \% \\
57,8 \%\end{array}$ \\
\hline $\begin{array}{c}\text { Total } \\
\text { Faria se serviço gratuito }\end{array}$ & 45 & $100 \%$ \\
\hline Sim & 43 & $95,6 \%$ \\
\hline $\begin{array}{c}\text { Não } \\
\text { Total } \\
\begin{array}{c}\text { Serviço gratuito seria adequado para a } \\
\text { formação }\end{array}\end{array}$ & $\begin{array}{c}2 \\
45\end{array}$ & $\begin{array}{c}4,4 \% \\
100,0 \%\end{array}$ \\
\hline Sim & 40 & $88,9 \%$ \\
\hline Não & 5 & $11,1 \%$ \\
\hline Total & 45 & $100,0 \%$ \\
\hline
\end{tabular}


O fato de24,4\%afirmarem que fazer psicoterapia causa algum desconforto enquanto acadêmicos de Psicologia implicam em uma resistência à procura de cuidados com a saúde mental, provocando um estado de alerta que movimenta o indivíduo a se proteger, delimitando sua exposição. O "expor-se" no processo psicoterapêutico coloca o indivíduo em contato com sua imagem real, podendo confrontá-lo com a idealização de si mesmo (VERZTMAN, 2014).

Percebe-se que questões econômicas são fundamentais para a tomada de decisão de iniciar ou mesmo dar continuidade à psicoterapia. As sessões terapêuticas são consideradas por $71,1 \%$ da amostra como um serviço "caro", o que corrobora com a afirmativa de $71,1 \%$ de que já deixaram de fazer psicoterapia por falta de condições financeiras. Nota-se que a faixa etária da amostra está em um momento de consolidação financeira e estruturação familiar como chegada de filhos, planejados ou não, custos com moradia, saúde e lazer.(MATOS e MAGALHÃES, 2014). Com o adendo dos investimentos na formação universitária, torna-se compreensível que fazer psicoterapia seja considerado dispendioso. Diante de uma renda média de dois salários mínimos, como apresentados nos dados socioeconômicos, há provável dificuldade e em conciliar todos os custos cotidianos. De acordo com a tabela de honorários do CFP (2016), a sessão de psicoterapia individual pode custar entre $\mathrm{R} \$ 142,67$, no limite inferior, $\mathrm{R} \$ 206,57$ em média e $\mathrm{R} \$ 244,59$ no limite superior, o que varia de acordo com a região do país, devido à realidade socioeconômica local.

A falta de tempo não configura argumento relevante à decisão de fazer psicoterapia para maior parte da amostra. Entretanto, 42,2\% apontam que esse fator é considerável. Não foram especificados os motivos dessa falta de tempo.

Os dados demonstram que $95,6 \%$ dos estagiários consideram a possibilidade de realizar psicoterapia, desde que de maneira gratuita, e concordam que isso é adequado para a sua formação, fator relevante para futuras pesquisas e intervenções no meio acadêmico. O CFP (2005) estabelece que a psicoterapia precisa ser paga, algo que se verifica que no Art. $4^{\circ}$, cujo texto aponta que para remuneração do trabalho do psicólogo, alguns critérios precisam ser atendidos: justa retribuição aos serviços prestados e às condições do usuário ou beneficiário; o valor de acordo com as características da atividade e a comunicação desta ao usuário ou beneficiário antes do início do trabalho a ser realizado, assegurando a qualidade dos serviços oferecidos independente do valor acordado. 
Conforme Gomes (2015) há no meio profissional quem considere que a psicoterapia gratuita não funcione, entre elas as oferecidas por "convênios", instituições ou por programas sociais, pois podem desequilibrar o sistema de troca em uma relação de doação mútua indo contra a dignidade do indivíduo, acarretando perda de tempo para o paciente que estaria de certa forma, miserável com ele mesmo e provavelmente não estaria realmente determinado a se "curar". Ainda segundo Gomes (2015), "se um paciente quer ser ajudado, ele não tem dificuldades em remunerar o seu profissional, e ao final, ele não vai ficar mais pobre por isto, uma vez que a longo prazo uma boa terapia acaba saindo de graça porque ela se paga".

Independente de paga ou gratuita, a necessidade de atendimento aos estudantes de Psicologia é notória tanto pelas dificuldades financeiras quanto pela realidade psíquica de cada um. Esse serviço seria um auxílio importante e ajudaria os estagiários a darem novos significados as suas vivências acadêmicas.

Andrade et al. (2016), a partir de uma pesquisa realizada com 119 alunos do curso de Psicologia de uma universidade pública do interior paulista, também apontou para a necessidade de serviços de atendimento psicológico para os alunos. Segundo o autor, as IES particulares tendem a adotar mais essa estratégia, enquanto há certa negligência por parte das IES públicas. O que é inegável é a necessidade de investigação sobre como conduzir esse processo.

\section{Conclusão}

Os acadêmicos de Psicologia concordam sobre a importância do "olhar para si", colocando-se no lugar de paciente, tendo suas demandas acolhidas e assim acolher as do outro, principalmente nessa etapa fundamental da graduação que é o estágio. Percebeu-se que existe a autoavaliação, mas que persistem as limitações financeiras responsáveis pelo adiamento da procura pela psicoterapia.

No processo de busca pelo referencial teórico, muito se leu sobre a importância da compreensão do contexto e mudanças sociais da população, sobre a competência técnica, ética e sobre a obrigatoriedade de ter um serviço de Psicologia que esteja atento à comunidade como exigência de formação do acadêmico da área. No entanto, pouco se lê sobre a importância da psicoterapia como extensão da formação do futuro profissional. Pouco se sabe sobre possíveis 
serviços de Psicologia direcionados ao tratamento pessoal do acadêmico como extensão de sua formação.

E assim ressalta-se a importância da psicoterapia pessoal já durante a graduação com o intuito de se colocar no lugar de paciente, tanto para conhecer o setting terapêutico quanto para tratar suas demandas psíquicas. Destaca-se, nesse quesito, a contribuição de Carl Gustav Jung:“‘ Conheça todas as teorias, domine todas as técnicas, mas ao tocar uma alma humana, seja apenas outra alma humana."

A pesquisa online, com instrumento estruturado por hipóteses, mostrou que alguns pontos poderiam ser mais bem explorados, talvez com mais opções nas perguntas fechadas ou através de respostas subjetivas como, por exemplo, o papel do estado civil no impacto sobre as impressões dos entrevistados. A ajuda de custo familiar seria para o pagamento da faculdade ou para custeio de despesas paralelas? A renda aproximada considerou, por parte do pesquisado, ganhos não formais como algum valor de bolsa auxílio ou mesada?

Sobre as questões favoráveis, que contribuem para que o estagiário faça psicoterapia, seria interessante abordar se a psicoterapia foi concluída, estava em andamento ou foi interrompida e por quais motivos e, no caso de aceitar um serviço gratuito, quais locais poderiam ser adequados de maneira que contribuíssem para sua formação.

Sugere-se novas pesquisas a partir das limitações encontradas nesse estudo e que informações sobre formas possíveis de voltar o olhar para a qualidade da formação do futuro psicólogo, através do acolhimento de suas demandas psicossociais, contribuam para debate entre acadêmicos e demais órgãos competentes, como Conselhos e Ministério de Educação. Assim, a possibilidade de avaliação e intervenção traria benefícios não só ao meio acadêmico, mas aos ambientes profissional e social.

\section{Referências}

ANDRADE, Antonio dos Santos et al.Vivências Acadêmicas e Sofrimento Psíquico de Estudantes de Psicologia. Psicol. Ciênc. Prof; Brasília, v. 36, n. 4, p. 831-846, dez. 2016.

CALLIGARIS, Contardo: Cartas a um Jovem Terapeuta. Rio de Janeiro: Elsevier, 2008-3 $3^{\text {a }}$ reimpressão. 
CAMBUÍ, Heloisa Aguetoni. NEME, Carmen Maria Bueno. Sofrimento psíquico contemporâneo: um estudo psicanalítico do imaginário coletivo de estudantes de psicologia. Revista Psicologia: Teoria e Prática, 2014, 16(2), 75-88.

COnselho Federal De PSICOlOGIA. Código de Ética Profissional do Psicólogo. Brasil: $\quad$ CFP, 2005, p. 5.Disponível em: $<$ http://site.cfp.org.br/wpcontent/uploads/2012/07/codigo-de-etica-psicologia-1.pdf>. Acesso em 30 de out. 2017.

Tabela de Honorários - Valores de Referência de honorários do psicólogo em (R\$). Atualizado pelo INPC - IBGE até fevereiro de 2016. Disponível em <http://site.cfp.org.br/servicos/tabela-de-honorarios/>. Acesso em: 12 de jan. 2017.

GIL, Antônio Carlos.1946. Como elaborar projetos de pesquisa. $5^{\text {a }}$. ed. - São Paulo, Atlas, 2010. Versão impressa: ISBN 978-85-22458233.

GOMES, J. C. A Psicoterapia precisa ser paga? Site do Psicólogo. 2015. Disponível em $<$ http://sitedopsicologo.com.br/a-psicoterapia-precisa-ser-paga.html>. Acesso em: 12 de nov. 2017.

JÚNIOR, E. G.; Feijó, M. R.; Cunha, E.V.; Corrêa, B. J. \& Gouveia, P. A. E. S. (2013). Exigências familiares e do trabalho: Um equilíbrio necessário para a saúde de trabalhadores e organizações. Pensando Famílias, 17(1), 110-122. Acesso em 27 out. 2017.

KICHLER,GiseldaFaes.SERRALTA,FernandaBarcellos.As Implicações da Psicoterapia Pessoal na Formação em Psicologia. Revista PSICO, e-ISSN:1980-8623v.45, n.1 (2014).

MANSO, Maria Elisa Gonzalez. A Resolução n 196/96 do Conselho Nacional de Saúde e o principialismobioético. 2012.

Disponível em:<http://www.egov.ufsc.br/portal/conteudo/resolu\%C3\%A7\%C3\%A3o-n\%C2\%BA19696-do-conselho-nacional-de-sa\%C3\%BAde-e-o-principialismo-bio\%C3\%A9tico>. Acesso em 18 jun. 2017.

MARCELLO, Fabiana de Amorim \& Fischer, Rosa Maria Bueno. Cuidar de si, dizer a verdade: arte, pensamento e ética do sujeito. Pro-posições | v. 25, n. 2 (74) | p. 157-175 | maio/ago. 2014, pág.165.

MATOS, Mariana Gouvêa de; MAGALHAES, Andrea Seixas. Tornar-se pais: sobre a expectativa de jovens adultos.Pensando fam., Porto Alegre, v. 18, n. 1, p. 78-91, jun. 2014.

MEIRA, Cláudia. HYALA,Mansilha Grupe; NUNES, Maria Lúcia Tiellet. Psicologia clínica, psicoterapia e o estudante de psicologia. Paidéia (Ribeirão Preto), Ribeirão Preto, v. 15, n. 32, p. 339-343, Dec. 2005.

OLIVEIRA, Cláudia de; JESUS, Paulo; JUNQUEIRA, Virgínia and UCHOA-FIGUEIREDO, Lúcia da Rocha. Histórias de vida e compreensão empática: uma pesquisa qualitativa sobre a estimulação da competência narrativa em estudantes de saúde. Ciênc. educ. (Bauru) [online]. 2016, vol.22, n.4, pp.975-991. ISSN 1516-7313. 
RESOLUÇÃO CNE/CES 5/2011.Diário Oficial da União, Brasília, 16 de março de 2011 $\begin{array}{lllllll}\text { Seção } & 1 & - & \text { p. } & 19 . & \text { Disponível }\end{array}$ $<$ http://portal.mec.gov.br/index.php?option=com_docman\&view=download\&alias=7692rces005-11-pdf\&category_slug=marco-2011-pdf\&Itemid=30192. Acesso em 9 nov. 2017>.

SEIXAS, Pablo de Souza. A Formação Graduada em Psicologia no Brasil: Reflexão sobre os principais dilemas em um contexto pós DCN. Natal, 2014. Disponível em:<http://repositorio.ufrn.br:8080/jspui/handle/123456789/17401>. Acesso em: 02 set. 2017.

SILVA, Karla Cristina da e SOARES, Ednei. A importância da psicoterapia pessoal para a formação do acadêmico em psicologia e psicólogo clínico. Disponível em https://www.portaleducacao.com.br/conteudo/artigos/psicologia/a-importancia-da-

psicoterapia-pessoal-para-a-formacao-do-academico-em-psicologia/56832. 2014. Acesso em: 18 jun. 2017.

VERZTMAN, Julio. Embaraço humilhação e transparência psíquica: o tímido e sua dependência do olhar.Ágora (Rio J.), Rio de Janeiro, v. 17, n. spe, p. 127-140, Aug. 2014.

XIII Plenário do Conselho Federal de Psicologia. Código de ética profissional do psicólogo, 2005. Disponível em <http://site.cfp.org.br/wp-content/uploads/2012/07/codigo-de-eticapsicologia-1.pdf $>$. Acesso em 18 jun. 2017.

YAMAMOTO, Oswaldo H.A LDB e a psicologia. Psicol. Cienc. Prof; Brasília, v. 20, n. 4, p. 30-37, Dec. 2000.

Como citar este artigo (Formato ABNT):

NUNES, Rosângela de Mello Owicki; SOUZA, Marjane Bernardy. A Terapia como Extensão na Formação do Acadêmico em Psicologia. Id on Line Rev.Mult. Psic., 2018, vol.12, n.42, p.56-69. ISSN: 1981-1179.

Recebido: 07/08/2018.

Aceito: 13/08/2018 